\title{
The Challenge of Training Translators and Interpreters in the Social Context of Foreign Unaccompanied Minors
}

\author{
Hanan Saleh Hussein \\ Department of Philology and Translation \\ Faculty of Humanities \\ Pablo de Olavide University, Seville, Spain \\ Email: hsalhus@upo.es
}

Received: $12 / 18 / 2020$

Accepted: $1 / 16 / 2021$

Published: $2 / 24 / 2021$

\begin{abstract}
:
There are many challenges facing teachers in the classroom, throughout the process of training translators and interpreters in higher education. This paper aims to share reflections and teaching practices related to the preparation of these future professionals, in the context of caring for a vulnerable group of the immigrant community, Unaccompanied Foreign Minors (UFM). The proposal is based on taking a step further in the Teaching Practice and Development (TPD) methodology of Specialized Translation and Bilateral Interpreting subjects by incorporating new knowledge such as that related to Public Management or Social Sciences. This is due to the firm belief of the author of this manuscript in the quality of training from a multidisciplinary approach that will undoubtedly bring many more benefits, not only to the students, but also to UFM as a sensitive group, to the Administration as a competent body and, also, to the host society. This proposal arises from a simple question: Are future translators and interpreters prepared to manage their work in a vulnerable context? To answer this question, it is necessary to analyze the practical knowledge acquired by these professionals in the preparation phase. Thus, the main objective of this work is to demonstrate that the use of real texts in the Translation and Interpreting classroom is a bet that leads to an excellent academic training. Furthermore, this multidisciplinary work will serve as a model to be followed by teachers in this field.
\end{abstract}

Keywords: Interdisciplinary, specialized Translation, training of translators and interpreters, unaccompanied foreign minors (UFM)

Cite as: Hussein, H. H. (2021) The Challenge of Training Translators and Interpreters in the Social Context of Foreign Unaccompanied Minors. Arab World English Journal for Translation \& Literary Studies 5 (1) 20 -39. DOI: http://dx.doi.org/10.24093/awejtls/vol5no1.2 


\section{Introduction}

This article investigates new methodologies in the classroom of practical teaching in Translation and Interpreting studies. The aim is to bring students closer to a social and legal reality in a specific work context through multidisciplinary material. This material consists of real and current texts used by the public entities that manage the care process for Unaccompanied Foreign Minors in Spain from three areas of knowledge: Translation and Interpreting of Arabic, English and French, Sociology and Public Law. The results of this work translate into the achievement of an integrated and useful training for the professional future of the students.

\section{Theoretical Framework}

The migratory movement of groups of Unaccompanied Foreign Minors (henceforth UFM) in Spain, especially in Andalusia, has had a social and political impact, especially in the last two decades. The vast majority of university students remain oblivious to the social, legal, administrative, economic and political dimensions of this phenomenon. These are groups of foreign minors who come mostly from North African and require protection and care from the authorities and official bodies, including non-governmental humanitarian organizations. It is a complex process involving various professionals such as social workers, specialists in the field of public management, and translators and interpreters, among others.

To get an idea of the dimension of the migratory effect on Spanish society and on Andalusian society, some quantitative data can be provided. The Guide to Initial Health Examination of Unaccompanied Foreign Minors (UFM) issued by Andalusia's Regional Department of Health and Family in June 2019, states that, according to the Information System for Minors (SIME) of the Andalusian Government, the majority of unaccompanied migrant children and adolescents who arrived in 2018 are from Morocco (63\%). Other frequent countries of origin are Guinea (14\%), Mali (9\%), Ivory Coast (5\%) and Algeria (2\%). Ninety-five per cent of these persons under 18 years of age are male. The profile of UFM has become more diversified, and it is very likely that this will continue, with children and adolescents arriving from other countries, some of which are unsafe and subject to serious social and political conflicts, increasing personal circumstances linked to traumatic experiences and family losses.

Furthermore, according to another report by Andalusia's Regional Department of Equality and Social Welfare (February 2019) $\mathrm{i}$, Andalusia is home to almost half the UFM that manage to reach Spain. Of the 10,162 undocumented children and adolescents without families that the Ministry of the Interior must monitor, 4,798 are cared for by Andalusia's welfare network, while the rest are distributed among the other Spanish regions. Whilst developing teaching innovation projects in the practical teaching sessions included in the Degree in Translation and Interpreting at the Universidad Pablo de Olavide (hereinafter DTI) ${ }^{\mathrm{ii}}$, which has been carried out with regard to the assistance and management of vulnerable groups of immigrants, refugees and asylum seekers, we noted the lack of resources available for the work assisted by qualified translators and interpreters during the primary phase of reception, identification and refuge. This lack of resources 
varies according to the classification of the managing body: public sector or the sector made up of humanitarian organizations that assist immigrants and UFM ${ }^{\mathrm{iii}}$. Since translation in the field of foreign nationals, immigration, refugee, and asylum is a new field of work where the services of translators and interpreters are requested, it believed that providing training for translation and interpreting students in a real context is an effective teaching method. Therefore, the purpose is to bring into the classroom a new methodology based on an approach that has been reset and synchronized with other areas of knowledge such as the field of Social Work and Public Management. This new methodological approach allows students to carry out translation and interpreting services from a global perspective, with core interdisciplinary knowledge that guarantees quality assistance to UFM as an unprotected sector in the host society (Alonso \& Ruiz, 2010).

There are many intended outcomes to be achieved by this action, including the following:

- To train students to deal with the difficulties that arise in the process of translation and interpreting caused by intercultural and psychological shock when assisting UFM.

- To reinforce the skills and sensitivity that stimulate students through logical thinking and from a multicultural perspective.

- To connect several areas of knowledge in order to work towards a shared responsibility that encourages collaborative work in groups of students from different areas and languages.

- To create a social and universal conscience from the field of transcultural research and to bring students closer to the legal and social reality of other parts of the world.

In addition to the general goals mentioned in the previous paragraph, another specific objective of this study is to investigate the feasibility of training translators and interpreters specialized in assisting immigrants and refugees in general, although, in this case, it is even more relevant to highlight the additional work taken on by all of them for the sake of protecting and monitoring the correct application of the protocol used in the assistance of UFM.

The starting premise is that multidisciplinary work is the most effective and appropriate practice for the achievement of the primary objective: updated TPD information that is materialized in the teachings delivered as part of the DTI. This methodology involves carrying out exercises and tasks that cover knowledge from the area of Sociology and Public Management. It follows guidelines that provide students with a better understanding of the social and legal reality of other parts of the world and help them to reflect on the adaptation of legal texts in the host societies within Europe. As there are few teaching manuals to approach $\mathrm{T}$ and I subjects from this three-dimensional approach, the author believes, even more, in the need for this type of action.

\section{Literature Review}

Classroom work in T and I, especially when it comes to Specialized Translation and Bilingual Interpreting, requires competence-based instruction. In this regard, supports the reflections of Álvarez (2004) about competence-based higher education, interdisciplinarity and 
autonomous student work. As the concept of competence becomes very broad, it allows us, in the case of our work, to include related and complementary knowledge in $\mathrm{T}$ and I. Hence, may be integrated into this methodological scenario social skills, legal knowledge, and social and cultural practices, among others, to achieve the task of "doing" and to teach students "know-how in context":

The concept of competence is diverse, depending on how you look at it, or the emphasis placed on one element or another, but the most widespread and accepted is that of "knowhow in context". "Know-how", far from being understood as "doing" just like that, requires knowledge (theoretical, practical, or theoretical-practical), affection, commitment, cooperation, and compliance, all of which is expressed in performance, also of a theoretical, practical or theoretical-practical nature. For example, when someone reads a text and interprets it (know-how), they perform an action (performance) in a theoretical context (content of the text). When an empirical mechanic repairs a vehicle (performance) they apply practical knowledge in an equally practical context (situation and conditions in which the performance occurs). (Álvarz, 2004, p.1)

On the other hand, it is agreed that interdisciplinarity is considered as a set of disciplines and as the pillar of the organization of integrated and transversal knowledge from the pedagogical point of view. In this sense, the opinion of Arrabal (2017: 6) is reaffirmed when he defines interdisciplinarity as "the crossing of boundaries, the opening to new spaces, the concern to respond to the real problems of the world, characterized by dynamism and flexibility". This thinking being akin to the philosophy of this work, its application has been carried out about the opening of new spaces such as those of the social sciences and legal sciences (Public Law) when elaborating the material for translation and interpreting practices in the higher education classroom. In this way, it is possible to respond to the real problems that arise in the work environment in the trajectory of future translators and interpreters in the context of managing the task with vulnerable groups such as UFM.

Other researchers assert that interdisciplinarity is an act of integration of several disciplines or fields of study and can exist within one or several educational institutions, as explained by Jacob (2015:2):

The terms ID and interdisciplinarity are often used interchangeably in the literature. 1 The former is an adjective and the latter a noun. ID practices in higher education refer to the integration of two or more disciplines or fields of study in relation to research; instruction; and program offerings, certifications, and/or degrees. Interdisciplinarity may exist within a single institution of higher education (HEI) or between two or more HEIs. There are many types of ID practices in the higher education literature.

Following these approaches from the formative point of view in higher education in which three different areas of knowledge work in an integrated manner within the same institution. This refers 
to the three arias mentioned above, all of which are located within the public institution of the Univ. Pablo de Olavide. Thus, the author chooses to a methodology of translatological practices in the classroom based on "knowing how to translate in a context of assisting UFM". To this end, texts from different official bodies and others from entities dedicated to assisting immigrants, refugees, and UFM are used. In another section, the main procedures carried out in the classroom and the results of the work will be presented, which will show the multiple interactions between teachers and the $\mathrm{T}$ and I teaching tools. Finally, we will draw some conclusions and indicate future lines of work in this same direction.

\section{Context of the Study}

To answer this question, it is necessary to briefly define which migrants are referred to when this acronym is used. The definition formulated by the Council of the European Union, set out in Article I of its resolution of 26 July 1977, defines an unaccompanied minor as:

A non-EU national or stateless person below the age of 18 who arrives on the territory of the EU States unaccompanied by an adult responsible for him/her, and for as long as s/he is not effectively taken into the care of such a person, including a minor who is left unaccompanied after s/he has entered the territory of the EU States. (97/C 211/03)

This group of minors requires the services of various professionals throughout Spain, as well as to have various needs met "in terms of education, health, accommodation, transition to adult life and social support" to adapt to the host context (Bravo \& Santo, 2017, pp. 55-62). It is then that translators and interpreters, social workers and technicians specialized in law enter the scene.

One of the aspects that most concern the staff in charge of UFM is the information that adolescents must provide about their history, family, and emotional life. If the information provided to the minors interviewed is incorrect or flawed, they may conceal or not want to share any information about themselves, as noted by Bravo and Santo (2017). Thus, great emphasis should be placed on the training of future translators and interpreters in this context.

Other research on UFM sheds light on a significant new migration strategy that requires attention from the legal sources of the law:

The law seeks to respond to this reality to balance the interests protected by the law on immigrants and the interest of the child, which is the core of child protection. There can be no doubt that the interest of the child - including the foreign child - must prevail because, according to the United Nations Convention, it is superior to any other interest. The following pages present the state of play and recent jurisprudential positions. In addition to its social importance due to the dimensions reached, the legal situation of foreign minors is of interest because of the concurrence of different public powers in the decision-making process, the plurality of protection regulations resulting from Spain's devolved government to the Autonomous Communities, and because the limited judicialization of the problem to date does not allow for rigorous scientific evaluation. (González, 2007, p. 149) 
Such statements reaffirm the need to introduce an interdisciplinary approach in Translation and Interpreting TPD classroom methodology as soon as possible.

In order to understand the particular vulnerability of UFM, refers to a classification mentioned in the Children's Conference "Proposals for a social protection strategy for children" held in April 2003 at the Training Seminar on "Legal Protection of Unaccompanied Foreign Minors", organized by Save the Children and the Universidad Pontificia Comillas de Madrid in September 2004 (González, 2007), which consists of the following:

- Unaccompanied minor children.

- Minor asylum seekers.

- Minors suffering from mental illness.

- Groups of children on the street.

Section one of the Guide to the Health Examination of UFMs published by Andalusia's Regional Department of Health and Family in June 2019, highlights the importance of communication with minors during the process to overcome language barriers through translation and interpreting. The Guide sets out the following recommendations:

- In the first interview, a climate of trust and friendliness should be promoted, avoiding as much as possible intimidating questions and invasive procedures. The development of the interview will be facilitated by the observation of the different emotional reactions of both the minors (fear, insecurity, distrust) and the health personnel (cultural difficulties, unknown pathologies).

- To overcome language and cultural barriers, a mediator should be present to provide an understanding of the language and culture. The APHS provides translation resources through "Health Service Responds" (phone: 955545060). It may be useful to contact NGOs in the area that regularly collaborate in the assistance of these people.

- The professional should address the child directly and at the same time, respect the necessary pauses for translation and/or interpreting.

- Since the vast majority of children who come to our Community are Moroccan or subSaharan, a grasp of and familiarity with some common terms will create a smoother and more open interview process (Annex 4).

- A sensitive approach is needed, in an enabling environment. Ask the minor about possible symptoms and always explain the examination to be carried out through the medium of a mediator/translator. Consider consulting the multidisciplinary group of MÉDICOS DEL MUNDO Málaga (952252377), malaga@medicosdelmundo.org (point 3.4)

As can be seen, the UFM context is a multidisciplinary professional field from which Translation and Interpreting TPD classroom methodology should not be excluded. 


\section{Training of Translators and Interpreters}

About the task of training translators and interpreters in general, it is necessary to stress the relevance of the sociological approach. This is because translation and interpreting are activities that are based on understanding the mechanisms underlying the task itself, as Wolf states in a paper on the didactics of translation (2010:337). In this sense, according to this author, research in this field has helped the creation of a new approach in the teaching of translation and interpreting, among them is the approach that embraces translation from a socio-political aspect, an aspect related to activism or what is called the engaged and activist approach, among others.

This reflection has been one of the axes of this work, since the task of translation and interpreting in the processes of care for UFM requires preparation based on the sociological approach. It can be said that this work context on which this research has been based could belong to what is called "committed approach".

In this same work on the didactics of translation, the researcher Kelly (2010: 394) discusses several approaches used in the classroom when training translators. Among them are Vienne's (1994) situational approach, Nord's translation approach and another approach that is of interest for this study and that is Daniel Gouadec's (1994) approach. The latter approach consists of the following:

A similar approach to training is that of Daniel Gouadec, who around the same date proposed incorporating real translation commissions for real clients into training programmes organized in workshops $(1994,2003)$. This same idea is later taken up by Kiraly in his second major publication on translator training.

This is where the focus of attention should be placed, since in this article the basis of the actions revolves around classroom work in a real context, with real people -in this case UFM-, with real documentation and in real situations. This makes the result of the methodology followed in the classroom for the training of students the most appropriate and effective.

Without going into detail on the issue of training for translators and interpreters, a brief allusion is made to the empirical studies that deal this reality and with regard to the training of translators and interpreters (Álvarez, 2004; Serrano, 2005; Garcés \& Cata, 2006, 2009, 2014, Nieto et al. (2009); among others). Throughout their cited research, these authors provide a vision of this field that reaffirms, even more, our multidisciplinary vision of formative action and which we apply in this work.

The need for methodological change responds to the evolution of today's labor markets and demands. These changes require certain adaptations, one of which pertains to the work of translators and interpreters in public services and official bodies. Research has led to programmes

Arab World English Journal for Translation \& Literary Studies 
that combine training with research and practice in multidisciplinary, multilingual, and multicultural contexts.

NGOs and the translation and interpreting services that are contracted or subcontracted by the Administration represent one of the scenarios in which translators and interpreters work. Hence, translation and interpreting services are required in all areas, including the field of immigration. Translation and Interpreting students represent the future liaison between the host society and different groups of immigrants, including UFM.

Therefore, to align the training of future professionals with the changing needs of society and the labor market, our purpose is focused on bringing updated texts into the classroom, thus providing students with the necessary information to meet the desired objectives. It must be produced translated materials aimed at UFM groups.

Linking teaching to the labor market and addressing the needs and shortfalls of students in training should be one of the most urgent priorities in the field of higher education in translating and interpreting.

Other research (Kelly, 1999, 2002; Way, 2002) on interdisciplinarity in the teaching of specialized translation confirms that this practice is becoming increasingly necessary in the training of professional translators and interpreters. This is because these professionals require specific information and knowledge in different areas, including the field of law, in order to clarify concepts, terms and major questions, with a tendency towards the global. This means that the translator and interpreter must become an expert who is called upon by clients for document translation assignments and interpreting services. There is a need for development in the training of translation skills, which the authors call "translation competence and sub-competence", which entails the active involvement of students throughout the learning process. These actions improve the student's ability to interact in their work context from a knowledge base characteristic of an expert in the client's own field of expertise. In our case, this argument helps us to apply this principle to the field of specialized translation for UFM groups. A translator with interdisciplinary knowledge covering translation tools and mechanisms, together with other knowledge related to Public Management in Law and/or basic skills in the field of Sociology, is a qualified translator, capable of managing a translation assignment for the Administration with all the necessary guarantees. Just like a translator, an interpreter will act under the same conditions. Moreover, this knowledge is most evident when an interpreter is working in a context involving minors. The research carried out by students of Translation and Interpreting in Arabic, English and French before translating texts or in preparation for Bilateral Translation practical assignments generates a higher degree of confidence both during the work process and in the results obtained. This same degree of effectiveness and confidence has been one of the key points displayed by translation and interpreting students of Arabic during their internships at the Seville Refugee Reception Center (CAR) during the 2017-2018 academic year.

Arab World English Journal for Translation \& Literary Studies 


\section{Methodology}

\section{Study of the Selected Corpus}

To proceed with the task of organizing the work, it is necessary to indicate that the texts selected for the translation process in the three working languages are texts and documents belonging to official bodies and entities such as: The Immigration Unit of the National Police of West Andalusia, the National Police Unit attached to the Regional Government of Andalusia, the Spanish Commission for Refugee Aid (CEAR) and the Seville Refugee Shelter (CAR):

- Preliminary report requests for the temporary displacement of foreign minors (LO 4/2000 and RD 557/2011).

- Minor Authorization Form.

- UFM interview questionnaire.

- Residency application form for the resident's children.

- Application form for the temporary transfer of minors.

- UFM NGO inclusion form.

The selected texts contain data relating to the competent body, either the Public Administration (Regional Government of Andalusia or the State) or the Humanitarian Organizations (NGOs). These data are found in the header of each document, so that students know the organizational reporting structure of each body.

The rest of the references are personal data, some of which are requested by the managing body. The language and terminology used in this sense are very varied, but most terms are from the judicial and legal field.

\section{Subjects involved in the project:}

Regarding the subjects involved in this methodological experiment have been the following subjects belonging to the academic year 2019-2020 of the Degree and Double Degree in Translation and Interpreting of the Faculty of Humanities at the Pablo de Olavide University:

- LCI Specialized Translation of the Arabic language, 3rd year of Degree and Double Honours Degree in T\&I.

- LCII Specialized Translation of the Arabic language, 3rd year of Degree and Double Honours Degree in T\&I.

- Interpreting Techniques B English L1, 4th year of Degree in T\&I.

- Terminology B French, 3rd year of Degree in T\&I.

- Interpreting Techniques B TPD 2-1, 4th year of Degree in T\&I.

- Other subjects involved in the project in order to use the results in the classroom for the benefit of the students:

- Public Management, 4th year of the Double Honours Degree in Law and Political Science of Administration.

- Basic Skills in Sociology, first year of the Degree in Sociology and Social Work.

Arab World English Journal for Translation \& Literary Studies 


\section{Methodology and classroom work}

It should be noted that, from the outset, the methodology used in the translation and interpreting classroom, in Arabic, English, and French, has considered a major factor in achieving optimal results. This factor seeks to awaken the interest of students in the qualitative values obtained in the texts and the tools made available to the students as material for the subjects in terms of assisting UFM groups. Furthermore, texts related to the basic skills required of a translator/interpreter in this work context are made available to the student. Hence, before beginning the process of translating the selected texts, the teachers provide the students with reading texts on the origin and history of the UFM groups and the regulations in force in the national and international spheres. Likewise, the way in which official bodies (Immigration Units and MENOR units) carry out the public management of UFM is detailed. In this way, the author starts from a globalized vision and gradually moves towards a translatological approach.

One of the aspects covered in practical classroom teaching is the analysis of the types of legal-administrative texts used when assisting UFM and aspects of these texts.

Selected texts for each TPD ${ }^{\text {iv }}$ session 4 are provided so that students can prepare a pretranslation analysis that will be reviewed and discussed in the classroom. Corrections will be made through a whole-class discussion, considering various alternatives and solutions to possible difficulties encountered, encouraging teamwork, and considering the cultural and linguistic diversity of the final recipient in the case of the child him or herself, or whether the final recipient is the administration.

Furthermore, to address the problems that arise in the process of translation and interpreting caused by intercultural clashes when assisting UFM, the following actions have been carried out:

Reading and discussion in the Virtual Classroom forums of the course about the legal and social aspects related to UFM.

Training and informative talks by associations and humanitarian organizations involved in the process of assisting UFM. These included talks given by technicians and social workers from entities such as: The Association for Cooperation and Development with North Africa $(\mathrm{CODENAF})^{\mathrm{v}}$ and the Spanish Commission for Aid to Refugees (CEAR) ${ }^{\mathrm{vi}}$.

Talks were also given by staff from the National Police Immigration Units in Andalusia. These are the officials responsible for activating the UFM protocol and oversee the documentation process from the beginning of the assistance phase up to the provision of accommodation in specialized centers run by Andalusia's Regional Government. 
Although it is not possible here to make a very broad analysis of the development of these activities, we do want to point out the relevance of this type of actions in which a further step is taken in the training of students from a sociocultural perspective.

Another of the activities processed in this regard is the presentation of the work undertaken by students from the three areas involved in the project by way of a conclusion. The result of this action is included as a basis for the work carried out during subsequent academic years in the same subjects. The analysis conducted by the students is clearly beneficial to other students following in their footsteps, as a chain of reflections and conclusions that affect their way of viewing this work context.

\section{4- Timing and schedule of the work:}

The following is the timeline of the temporization of the classroom work of all the subjects involved:

September /October 2019: (Common to all Degrees).

- Compilation and preparation of documents.

- Constitution of working groups of teachers and students in the Areas.

- Informative meeting between those responsible for the official bodies and teachers to define the tasks to be carried out.

- Organization of training activities for students.

- Distribution of the material to the work teams.

— Work planning.

A) For T\&I students:

October 2019 / February 2020:

- 1st phase of translation of documents by the students and revised by the teaching staff. February 2020:

- Conduction of a first evaluation by students and faculty.

- Preparation of a guide of difficulties and incidents during the translation process.

- Elaboration of interviews with those responsible involved in the process of implementation of the protocol of care for UFM in Seville, in all the languages involved.

February / April 2020:

- Corrections of the 1 st phase.

- 2nd phase, consisting of the translation of the documents used in the protocol with supervision of the teachers.

- April 2020: Quality control of the translations.

- June 2020: Preparation of the final material: translated documents.

- Elaboration of a general evaluation guide and a guide that collects the work done in all the languages involved.

B) For students of the Sociology and Public Management Degrees:

October 2019 / February 2020: 
- Each group of students will submit the papers with a commentary related to the requirements of the subject in question.

- The professor proceeds to the correction of the students' work.

- Generate a debate in class on the social reality and possible changes that could be introduced in this type of texts, in order to meet the needs of foreign minors given the case that they are not entitled to legal aid.

February / April 2020:

- Elaboration by the students of a critical analysis based on the basic competences and reflecting the skills related to each of the branches of these two subjects.

- Carry out an evaluation by the teaching staff of said analysis and the sharing of the results of the work in each subject.

June / October 2020: (Common to all Degrees)

- Dissemination and publication of the results of the research work carried out.

\section{Results and discussion}

Since this activity is classified as a teaching innovation action in the classroom involving three different branches of knowledge (Humanities, Law and Social Sciences), it is extremely necessary to verify the degree of fulfillment of the objectives set, the following evaluation actions are proposed:

- The elaboration of questionnaires/surveys both quantitative and qualitative to evaluate the activity from the students' perceptions regarding the difficulties encountered.

- This evaluation will be carried out individually for students of the Degree in Translation and Interpreting, students of Public Law and students of Sociology and, finally, a general evaluation common to all the subjects involved will be carried out as a final evaluation.

- Likewise, students will be able to express their degree of satisfaction and the learning support provided by the activity. In the same way, the degree of professional interest that this activity awakens in the students of each area will be evaluated.

- The opinions of the participating teachers will be evaluated to improve future research teaching actions along the lines of this activity and to detect the students' shortcomings when dealing with the management and work in this area.

- A report on the results of the work carried out by the students will be sent to the organizations involved in this action. Also, their opinion will be requested on the subject and the evaluation of the degree of usefulness of this type of actions. To this end, specific questionnaires will be prepared to determine how the results of this work would help to improve the attention to UFM in the reception and identification phase.

- On the other hand, teaching materials will be developed for the practice of this type of texts in the classroom. Likewise, an analysis will be carried out to detect the students' shortcomings and difficulties for future translation and interpretation work, work related to the sociological analysis of intercultural and interlinguistic mediation in vulnerable sectors, and work related to the analysis of public law in this field. 
The results of this work have been directly reflected in the following actions:

- The research topics for final degree dissertations in the T\&I Department include this field as an alternative for working with students, and they have selected the topic as an option.

- The students have chosen to complete their internships in UFM's Center.

- The training sessions organized by the teaching team and attended by technicians from the entities involved in assisting UFM have borne fruit in the form of students volunteering as translators and interpreters.

Another of the key outcomes, which cannot yet be quantified, is social awareness. The methodology followed in this work generates discussion both in the classroom and in discussion forum activities that demonstrates the knowledge gained about this issue at a personal and social level. This is undoubtedly a valuable contribution to the training of future translators and interpreters, as stated by authors such as Cano (2014), Díaz et al. (2018) or Garcés (2011).

Regarding future projection, this classroom teaching innovation action aims to train students from three different areas, using a transversal, socio-cultural and linguistic approach, as an alliance of social commitment and research. Thus, students who are studying the specific competencies of Translation and Interpreting also acquire the transversal skills of Political Law and Sociology. The same applies to each of the subjects taught on the other two Degrees. The teachers participating in this Action instruct their students in a methodology that goes beyond the simple translation of a source text into a target text, and which is grounded in the analysis of social reality and the handling of that reality by Public Administration.

This will allow us to undertake new didactic work based on this three-dimensional approach, which can provide new alternatives to the texts used when receiving and identifying vulnerable foreign minors. These alternatives will improve the management of Public Administrations and humanitarian organizations when dealing with UFM.

As an example, one of the questionnaires carried out in the Public Management classroom is shown below:

\section{PUBLIC MANAGEMENT - TEACHING INNOVATION PROJECT}

"Multidisciplinary work on the process of care for Unaccompanied Foreign Minors (UFM) in Andalusia: Sociology, Public Law and Translation and Interpreting areas."

- QUESTIONNAIRE

- How are UFM's Centers managed?

- What services are offered?

- How are the services provided evaluated?

- Analyze

- Necessary documentation 
https://www.juntadeandalucia.es/organismos/igualdadpoliticassocialesyconciliacion/areas /infancia-familias/separacion-familia/paginas/acogimiento-residencial.html https://www.samu.es/

Lecture notes on management modalities and public/private partnerships

1. UFM's centers are:

a. Privately owned centers that are managed with private funds.

b. Publicly owned centers that are managed by a public administration.

c. Publicly owned centers that are managed by a private entity.

2. The management modality of the UFM's centers is a
a. Privatization
b. Outsourcing
c. Direct management by a public administration

3. Direct management of a public service

a. It never involves collaboration with other actors

b. It may involve collaboration with other actors

c. Always involves collaboration with other actors

4. What type of public-private collaboration is carried out in the UFM System of Care?
a. Service Contracts
b. Concessions
c. Agreements

(Explain)

5. What types of agreements can be carried out by the Department of Equality, Social Policies and Conciliation?

a. Collaboration agreements

b. It is not competent to sign agreements

c. Collaboration, coordination, and consultation agreements

6. Between what types of entities is a Collaboration Agreement executed?
a. Between public and private entities
b. Between public entities
c. Both above are correct

7. What programs does SAMU offer in relation to UFM's?
a. They are varied and depend on the situation and age of the minor.
b. Foster care program
c. Health care

8. Do UFM's centers offer translation services?
a. Yes
b. No
c. I don't know

9. To what extent are/would Translation services be important?
a. Not at all
b. Not very

Arab World English Journal for Translation \& Literary Studies ISSN: 2550-1542 | www.awej-tls.org 
c. Quite a bit

d. A lot (Justify)

10. What is a Service Charter?

a. An instrument to promote the quality of public services.

b. An instrument to promote the efficiency of public services.

c. Instrument to promote the efficiency of public services.

11. What is a Quality Commitment?

a. A general statement on the quality of a service

b. An objective that is set to achieve quality in the service.

c. A contract with the customer of the service

12. How is a quality commitment measured/evaluated?

a. According to its adequacy to the general objectives of the organization.

b. By analyzing the clauses of the contract

c. By establishing indicators

13. Do the entities that manage the reception of UFM's have Service Charters?
a. Yes
b. No
c. I don't know

Make an evaluation on the management modality of the UFM's centers and indicate at the end what you thought of a practice on this subject.

\section{Conclusion}

The impetus for this work has been that the author has realized that the texts used in the practices of university teaching in the Degree of Translation and Interpreting are not adequate to the new contexts of work in professional life. Thus, the purpose of this research is to offer a vision of the training situation of T\&I students from a multidisciplinary point of view and specifically, in the context of dealing with and assisting UFM groups.

Analyzing the actions carried out in the classroom with respect to practical Translation and Interpreting teaching through this methodological innovation action, the training of translators and interpreters depends to a great extent on the teaching received at university level. In this respect, it is believed that one of the most effective tools in preparing students to face the problems they will encounter in the professional field is to offer an interdisciplinary approach.

This action reinforces the skills and sensibilities that stimulate students and provides them with a logical way of reasoning from an intercultural point of view. It is known from the comments in the discussion forums that our students acquire a new capacity to ask questions for research, from a comprehensive viewpoint. The practice of professional translators and interpreters with this 
vulnerable group is a responsibility that must be undertaken and developed with the necessary scientific knowledge, but in an honest way and with the utmost care.

The students are strengthened through collaborative work with groups from different disciplines that helps to create a social and universal conscience from the field of cross-cultural research.

Undoubtedly, future translators and interpreters who have been able to carry out their practical studies grounded in a current and updated reality will be able to face any problems that arise in a more decisive way. Along the same lines, the texts translated into the three working languages (Arabic, English and French) are proving useful for the task of preparing teaching materials for the translation and interpreting classroom in these three languages.

Finally, it is believed that this work represents an aid to future translation and interpreting professionals to become familiar with their working environment. This is clearly an advantage that will favor the development of the task in the best possible way, increasing the quality of the results obtained. Likewise, our results point to certain trends that could serve as an experimental methodological basis for future actions in the T and I classroom.About the Author:

\section{About the Author:}

Dr. Hanan Saleh Hussein is a PhD Associate Professor in the Area of Arabic and Islamic Studies in the Department of Philology and Translation at the Pablo de Olavide University in Seville since 2010. She studied Hispanic Philology and T\&I at the University of Ain Shams (Egypt). She is a translator and interpreter in the private and judicial field and a teacher and trainer in the field of Arabic language and culture for the National Police Force. ORCID: http://orcid.org/0000-00016905-4267

\section{References}

Alonso, I. M., \& Ruiz, F. P. (2010). Menores Extranjeros No Acompañados (MENA), Un colectivo especialmente vulnerable ante las drogas [Unaccompanied Foreign Minors, A group particularly vulnerable to drugs]. Zerbitzuan: Gizarte zerbitzuetarako aldizkaria= Revista de servicios sociales, 48, 71-85.

Álvarez, R. P. (2004). Formación superior basada en competencias, interdisciplinariedad y trabajo autónomo del estudiante [Higher education based on competencies, interdisciplinarity and autonomous student work]. Revista iberoamericana de educación, 35 (1), 1-33.

Arrabal, N. A. (2017). La interdisciplinariedad como elemento clave en la conceptualización de los Estudios de Traducción en el campo de conocimiento [Interdisciplinarity as a key element in the conceptualization of Translation Studies in the field of knowledge]. SKOPOS. Revista Internacional de Traducción e Interpretación, 8, 3-26. 
Bravo, A., \& Santos-González, I. (2017). Menores extranjeros no acompañados en España: necesidades y modelos de intervención [Unaccompanied foreign minors in Spain: needs and intervention models.]. Psychosocial Intervention, 26, 55-62.

Cano, A. G. (2014). La planificación de la actividad docente en el proceso de enseñanzaaprendizaje: Traducción y Derecho/Planning for teaching in the teaching-learning process: Translation and Law. Historia y Comunicación Social, 19, 525-538.

Díaz Alarcón, S. et al. (2018): Manual didáctico en soporte virtual para la práctica de la traducción especializada [Virtual didactic manual for specialized translation practice].

Garcés, C. V. (2009). Inmigración y servicios de traducción en España [Immigration and translation services in Spain]. Lengua y migración/Language and Migration, 1 (2), 57-72.

Garcés, C. V. (2011). Nuevos caminos con buenos maestros en Traducción e Interpretación. En homenaje a Valentín García Yebra [New paths with good teachers in Translation and Interpreting. In homage to Valentín García Yebra]. Mutatis Mutandis, 4 (2), 155-171.

Garcés, C. V. (2014). Formación de traductores e intérpretes en una sociedad multicultural. El programa de la Universidad de Alcalá, Madrid [Training translators and interpreters in a multicultural society. The program of the University of Alcalá, Madrid]. Cuadernos de ALDEEU, 25, 215-238.

Garcés, C. V., \& Cata, L. (2006). Acción y voluntariado: las ONG y los servicios de traducción e interpretación [Action and volunteering: NGOs and translation and interpreting services]. Revista española de lingüística aplicada, 1, 49-60.

González, I. L. (2007). Menores extranjeros no acompañados. La situación en España [Unaccompanied foreign minors. The situation in Spain]. Prolegómenos, 10 (19), 149-162.

Jacob, W. J. (2015). Interdisciplinary trends in higher education. Palgrave communications, 1 (1), $1-5$.

Kelly, D. (1999). Proyecto docente e investigador. Granada: Universidad de Granada [Teaching and research project. Granada: University of Granada].

Kelly, D. (2002). Un modelo de competencia traductora: bases para el diseño curricular [A model of translation competence: basis for curriculum design]. Puentes, 1 .

Kelly, D. (2010). Translation Didactics. Handbook of Translation Studies, 1, 389-396.

Nieto, M. T. S., et al. (2009). Experiencias de colaboración interdisciplinar en Traducción e Interpretación [Experiences of interdisciplinary collaboration in Translation and Interpreting]. @ tic. revista d'innovació educativa, 3, 52-61.

Serrano, M. B. M. (2005). Consideraciones fundamentales en la formación de traductores: mercado de trabajo y tipo de alumnado. TRANS: revista de traductología, 9, 195-202.

Way, C. (2002). Traducción y Derecho: iniciativas para desarrollar la colaboración interdisciplinar [Translation and Law: initiatives to develop interdisciplinary collaboration]. Puentes: hacia nuevas investigaciones en mediación intercultural [Bridges: towards new research in intercultural mediation], 2, 15-26.

Wolf, M. (2010). Sociology of translation. Handbook of translation studies, 1(2), 337-343.

Arab World English Journal for Translation \& Literary Studies 


\section{Websites:}

https://www.juntadeandalucia.es/export/drupaljda/Gu\%C3\%ADa_MENA2019_DEF_0.pdf: Guía para examen de salud inicial de Menores Extranjeros No Acompañados (UFM), Consejería de Salud y Familias de la Junta de Andalucía, junio 2019 [Guide for initial health screening of Unaccompanied Foreign Minors, Consejería de Salud y Familias de la Junta de Andalucía, June 2019]. [7.06.2020]

http://www.codenaf.org/ [7.06.2020]

https://www.cear.es/ [7.06.2020]

\section{Annexes in source language}

Texts for translation practice in the context of UFMs Source text in Spanish for translation into the three languages: Arabic, English and French.

Source: Ministry of the Interior, Government of Spain, Citizen's Service, Foreign Minors: http://www.interior.gob.es/web/servicios-al-ciudadano/extranjeria/regimen-general/menoresextranjeros

\section{Appendices}

Texts of the annexes translated from the source language (Spanish) to English.

\section{Appendix A}

Text One: UFM coming of age regulations.

\section{Coming of age}

The minors under guardianship who have a residence permit and reach the age of majority may request the renewal of the permit. For its renewal, which will take into special consideration the degree of integration of the applicant into Spanish society, the same procedure will be followed as that established for the renewal of a temporary non-profit residence permit, although the amount to be accredited as economic means for its maintenance is established in an amount that represents $100 \%$ of the Public Indicator of Income from Multiple Effects (IPREM) monthly.

The validity of the renewed authorization will be two years unless a long-term residence permit is required.

At the time of their coming of age or during any subsequent moment, they may request the modification of the current residence authorization to obtain a residence and work authorization.

In the case of minors for whom a child protection service has legal guardianship, custody, provisional protection, or guardianship, who reach the age of majority without having obtained a residence permit and have participated adequately in the training and activities planned by that entity to promote their social integration, it may recommend the granting of a temporary residence permit in exceptional circumstances. If it is granted, a temporary residence permit or residence and work permit for employees or self-employed persons will be granted.

The application for temporary residence authorization due to exceptional circumstances shall be submitted in person by the foreigner to the Immigration Office for the province in which he or she is domiciled during the sixty calendar days prior to or during the ninety calendar days 
following the date on which he or she turns eighteen, and he or she must provide proof of this alternatively:

1. That he has sufficient economic means to support himself, in an amount representing $100 \%$ of the IPREM monthly.

2. That he has a work contract or contracts of successive duration and meets the requirements established for such purpose.

3. Who meets the requirements established for the exercise of a self-employed activity? However, the expected return on the project must be, at least, an amount to ensure the expenses related to their food and accommodation that represents $100 \%$ of the IPREM monthly.

\section{Appendix B}

\section{Text Two: UFM regulations on repatriation}

\section{Repatriation of the unaccompanied foreign minor}

The Delegation and Sub-delegation of the Government in whose territory the home of the minor is located will be competent to carry out the procedures related to the repatriation of an unaccompanied foreign minor, including the practice of previous informative actions and, if necessary, the initiation, processing, and resolution of the repatriation procedure.

The Government Delegation or Sub-delegation, through the General Commissioner for Foreigners and Borders, will request a report from the diplomatic representation of the child's country of origin on the child's family circumstances, as well as any information on the child's situation from the entity that has been assigned legal guardianship, custody, provisional protection, or care.

The procedure for the repatriation of the child shall be initiated when, according to the reports, it is considered that the best interests of the child are served by reuniting him/her with his/her family or by making him/her available to the protection services of his/her country of origin.

Once the established procedures have been completed (allegations, evidence, etc.), after having heard the minor if he or she has sufficient evidence, and after receiving a report from the child protection services and the Public Prosecutor's Office, the State Administration will decide, in accordance with the principle of the best interests of the minor, on the repatriation of the minor to his or her country of origin or to the country where his or her family is located, or on his or her stay in Spain.

Those over sixteen and under eighteen years of age will be recognized as capable of acting in the repatriation procedure, as well as in the contentious-administrative jurisdictional order for the same purpose and may intervene personally or through the representative they designate.

In the case of minors under sixteen years of age, with sufficient judgment, who have manifested a will contrary to that of the person who holds their guardianship or re-presentation, the course of the procedure shall be suspended until the appointment of the judicial defender to represent them. Without prejudice to the fact that this degree of maturity may be appreciated at a lower age, it shall be understood that the foreigner over twelve years of age has sufficient judgment.

Arab World English Journal for Translation \& Literary Studies 
If the repatriation is resolved, it will be carried out either through family reunification or by making the child available to the child protection services of the country of origin.

If the minor is involved in a legal process and this fact is accredited in the administrative file of repatriation, the execution of this will be conditional on judicial authorization.

\section{Appendix C}

\section{Text Three: UFM residence regulations}

\section{Residence of the unaccompanied foreign minor}

If it is proven that it is impossible to repatriate the minor, and in any case after nine months have passed since the minor was placed at the disposal of the competent services for the protection of minors, a residence permit will be granted.

The procedure may be initiated ex officio by the Aliens Office of the province in which the child's domicile is located, or by superior order, or at the request of the child protection service.

\section{Documentation}

- In the event of having initiated the procedure ex officio, the Aliens Office will communicate the agreement to begin and will require the mandatory documentation from the child protection service.

- In the case of initiation at the request of the child protection service, at the Aliens Office of the Government Delegation or Sub-delegation of the province in which the foreign minor has set his or her home, the application form (EX-01) must be submitted in duplicate, duly completed, and signed by the child protection entity.

- Original and copy of the complete passport, travel document or valid identity card of the minor.

- Documentation accrediting the representation of the service of protection of minors in favor of the natural person who presents the application.

- Documentation accrediting the legal guardianship, custody, provisional protection, or guardianship between the minor and the protection service.

— Decree, Agreement or Resolution of the Public Prosecutor's Office of making available.

i. https://www.juntadeandalucia.es/boja/2019/31/11

ii. This information refers to "Action 2" teaching innovation projects carried out by the author of this work as coordinator of a teaching team during the 2017/201/ and 2018/2019 academic years. The projects have been managed in classrooms with real material belonging to the Seville Refugee Reception Center (CAR).

iii. The title of the teaching innovation project is "Multidisciplinary work on the process of care for unaccompanied foreign minors in Andalusia: Areas of Sociology, Public Management and Translation and Interpretation".

iv. Practical and developmental lessons.

v. http://www.codenaf.org/

vi. https://www.cear.es/ 